\title{
Imaging of Myocardial Fibrosis and Its Functional Correlates in Aortic Stenosis: A Review and Clinical Potential
}

\author{
Asim Katbeh $^{\mathrm{a}, \mathrm{b}}$ Tomas Ondrus ${ }^{\mathrm{a}}$ Emanuele Barbato $^{\mathrm{a}, \mathrm{b}}$ Maurizio Galderisi ${ }^{\mathrm{b}}$ \\ Bruno Trimarco $^{b}$ Guy Van Camp ${ }^{a}$ Marc Vanderheyden ${ }^{a}$ Martin Penicka ${ }^{a}$ \\ ${ }^{a}$ Cardiovascular Center Aalst, OLV Clinic, Aalst, Belgium; b Department of Advanced Biomedical Sciences, \\ University of Naples Federico II, Naples, Italy
}

\section{Keywords}

Aortic stenosis - Cardiac magnetic resonance .

Myocardial fibrosis - Speckle tracking echocardiography .

Left ventricular function myocardial fibrosis in patients with severe AS and to explore their relation with myocardial function, determined by STE, as well as the prognostic and diagnostic potential of both parameters.

(c) 2018 S. Karger AG, Basel

\begin{abstract}
Patients with severe aortic stenosis (AS) show progressive fibrotic changes in the myocardium, which may impair cardiac function and patient outcomes even after successful aortic valve replacement. Detection of patients who need an early operation remains a diagnostic challenge as myocardial functional changes may be subtle. In recent years, speckle tracking echocardiography (STE) and cardiac magnetic resonance mapping have been shown to provide complementary information for the assessment of left ventricular mechanics and identification of subtle damage by focal or diffuse myocardial fibrosis, respectively. Little is known, however, about how focal and diffuse myocardial fibrosis occurring in severe AS are related to measurable functional changes by echocardiography and to which extent both parameters have prognostic and diagnostic value. The aims of this review are to discuss the occurrence of focal and diffuse
\end{abstract}

\section{Introduction}

The appropriate timing of aortic valve replacement (AVR) in asymptomatic patients with severe aortic stenosis (AS) remains challenging $[1,2]$. Several of these patients show progressive fibrosis of the left ventricular (LV) myocardium, which may impair cardiac function and clinical outcomes even after successful AVR [3-5]. These individuals may benefit from early AVR before the development of irreversible myocardial fibrosis. The identification of myocardial damage at an early stage remains challenging. Indices provided by standard echocardiography show a low sensitivity as myocardial structural and functional changes may be subtle. Cardiac magnetic resonance (CMR) and speckle tracking echocardiography (STE) have been recently shown to provide complementary in-

\section{KARGER}

(c) 2018 S. Karger AG, Basel

E-Mail karger@karger.com

www.karger.com/crd
Martin Penicka, MD, PhD

Cardiovascular Center Aalst, OLV Clinic

Moorselbaan 164

BE-9300 Aalst (Belgium)

E-Mail martin.penicka@olvz-aalst.be 
formation in the assessment of myocardial fibrosis and its functional consequences, respectively [6-9]. However, information on the clinical value of the use of these cardiac imaging techniques in valvular heart disease is scant. Moreover, little is known about the relationship between myocardial fibrosis and measurable LV systolic function by STE. Accordingly, the aim of the present paper is to review the existing scientific literature on the relation between myocardial fibrosis and LV dysfunction and its possible impact on clinical outcomes in patients with AS.

\section{Pathophysiology of LV Dysfunction in AS}

Obstruction of the LV outflow tract due to AS is associated with a gradual increase in the LV afterload, which ultimately leads to the development of LV hypertrophy. Until recently, LV hypertrophy in AS had been considered a compensatory mechanism of the left ventricle muscle to face the high-pressure overload. Hypertrophied LV is capable of generating greater forces and higher pressures, while the increased wall thickness maintains a normal wall stress and sustains LV contractions. However, this original view of LV hypertrophy as a solely compensatory process has changed in the last decades. Focused papers have in fact demonstrated a significant relationship between LV hypertrophy and increased LV stiffness, diastolic dysfunction, and increased LV filling pressure [10-12]. Thanks to recent advances in cardiac imaging, a close association has been observed between the development of LV hypertrophy and myocardial fibrosis [13]. It has been postulated that, while originally being a compensatory process, LV hypertrophy ultimately becomes maladaptive and leads to myocyte apoptosis and diffuse interstitial myocardial fibrosis. These changes make the cardiac muscle less compliant and are responsible for the progression of LV hypertrophy towards overt heart failure [14-16]. Cardiac fibrocyte cells normally produce collagen to provide structural support for the heart. When overactivated in response to pressure overload, this process causes excessive accumulation of fibrosis and damages myocardial muscles. In histology, 2 types of myocardial fibrosis have been described: diffuse myocardial fibrosis (DMF), an early form of fibrosis believed to be reversible, and focal myocardial fibrosis (FMF), a later form that is irreversible [17]. AS is characterized by a significant increase in DMF, with a large variation in interindividual values $[6,17]$. The extent of DMF has been shown to be an independent predictor of adverse clinical outcomes both before and after AVR as well [15,
$18,19]$. Notably, patients with paradoxical low-flow lowgradient AS have a higher degree of myocardial fibrosis and LV longitudinal dysfunction than patients with normal-flow high-gradient AS $[16,20]$. It has been hypothesized that not only a reduced LV cavity but also LV functional changes as a consequence of myocardial fibrosis contribute to a reduction in the LV stroke volume and production of a low transvalvular gradient, thus leading to a poor outcome $[20,21]$. This suggests that DMF may be one of the critical mechanisms underlying the transition of LV hypertrophy to heart failure with an unfavorable clinical course. Accordingly, an accurate diagnostic technique, able to assess DMF or its functional correlates, may be crucial in patients experiencing AS.

\section{Imaging of Diffuse Myocardial Fibrosis in AS}

LV myocardial biopsy has been the gold standard for evaluation of DMF for a long time. However, the invasiveness, susceptibility to sampling errors, and inability to assess the fibrotic burden of the whole LV myocardium hamper its clinical utility in daily practice. CMR has emerged as a reference noninvasive method to assess both FMF and DMF $[6,15,26]$. Late gadolinium enhancement (LGE) at CMR is an established technique for assessing FMR (replacement fibrosis, scar). In symptomatic patients with severe AS, FMF occurs mainly in the subendocardial layer of the LV and its degree decreases from the base to the apex $[15,16]$. Patients with a larger extent of FMF had a significantly lower freedom from cardiac death at 10 years $(42 \pm 19 \%$ vs. $89 \pm 6 \%, p=0.002)$, with congestive heart failure being the most common cause of death [3]. In another study, the presence of FMF was significantly associated with poor postoperative outcomes [17]. However, FMF develops later in the disease course and, therefore, CMR-derived LGE is not sensitive enough to detect the early stage of myocardial damage. Accordingly, in our previous studies which used CMR-derived T1 mapping (CMR-T1), a total of $25 \%$ of patients had extensive (>30\%) DMF and a focal scar was not observed in any of them $[23,24]$. Using the MOLLI sequence, CMR-T1 was in fact recently shown to allow accurate detection and quantification of DMF with excellent precision, reproducibility, and scan-rescan stability [22]. The T1 mapping technique measures the myocardial T1 relaxation time before or after contrast administration. An increased collagen content with expansion of the extracellular space causes prolongation of the native T1 relaxation time and an extracellular volume (ECV) fraction 
Table 1. Advantages and limitations of STE and CMR mapping in AS assessment

\begin{tabular}{|c|c|c|}
\hline & STE & CMR mapping \\
\hline \multirow[t]{4}{*}{ Advantages } & $\begin{array}{l}\text { Low cost, more availability, rapid measurement offline after } \\
\text { adequate image acquisition }\end{array}$ & $\begin{array}{l}\text { Ability to image on any plane, full visualization of the } \\
\text { myocardium, valve inflow/outflow tracts }\end{array}$ \\
\hline & $\begin{array}{l}\text { Non-Doppler, angle-independent, myocardial deformation } \\
\text { evaluated in } 2-\mathrm{D} \text { and } 3-\mathrm{D} \text {, good reproducibility }\end{array}$ & $\begin{array}{l}\text { Direct measurement of the valve area and } \\
\text { characterization of the associated great vessel anatomy }\end{array}$ \\
\hline & Objective quantification of myocardial systolic dynamics & $\begin{array}{l}\text { Gold standard to quantify valve flow, cardiac volumes, } \\
\text { and mass }\end{array}$ \\
\hline & $\begin{array}{l}\text { Recent data support GLS derived by STE as a sensitive } \\
\text { marker to detect subclinical myocardial dysfunction in AS } \\
\text { patients }\end{array}$ & $\begin{array}{l}\text { CMR techniques such as LGE and T1 mapping are } \\
\text { promising markers to detect focal and diffuse } \\
\text { myocardial fibrosis, respectively }\end{array}$ \\
\hline \multirow[t]{3}{*}{ Limitations } & Lower temporal resolution, need for good image quality & High cost, limited availability \\
\hline & Tracking affected by out-of-plane cardiac motion & Adverse reaction to gadolinium \\
\hline & Intervendor variability & $\begin{array}{l}\text { Relative complexity of acquisitions, time-consuming } \\
\text { image analysis }\end{array}$ \\
\hline
\end{tabular}

AS, aortic stenosis; CMR, cardiac magnetic resonance; DMF, diffuse myocardial fibrosis; ECV, extracellular volume; GLS, global longitudinal strain; LGE, late gadolinium enhancement; STE, speckle tracking echocardiography.

increase in comparison with normal myocardium. Both native T1 relaxation time and ECV have been significantly associated with DMF at myocardial histology [25-27]. We recently reported the high accuracy of both native T1 relaxation time with a cut-off value $\geq 1,010 \mathrm{~ms}$ ( $\mathrm{Ss}=90 \%$, $\mathrm{Sp}=73 \%$, AUC $=0.82)$ and ECV with a cut-off value $\geq 0.315$ (Ss $=80 \%, \mathrm{Sp}=90 \%, \mathrm{AUC}=0.85$ ) to identify extensive (>30\%) DMF at histology [24]. Moreover, correlations between both native T1 and ECV with prognostic markers such as NT-pro-BNP or troponin have been reported $[28,29]$. CMR-T1 has therefore been proposed as a promising technique to identify early structural changes in patients with AS. The advantages and limitations of CMR in AS assessment are shown in Table 1.

\section{Imaging of Early LV Dysfunction in AS}

LV ejection fraction by echocardiography is routinely used to assess LV systolic chamber function in patients with AS. However, increasing evidence demonstrates that irreversible myocardial damage might occur before changes in the ejection fraction become apparent [8]. It is noteworthy that AS-induced DMF starts at the subendocardial level, affecting mainly longitudinal LV function. Since it is predominantly determined by radial function, the LV ejection fraction can be normal for a long time even in the presence of extensive subendocardial fibrosis
$[6,15,19]$. Accordingly, the LV ejection fraction, i.e., the class I guideline recommendation for AVR, cannot be used for early risk stratification in asymptomatic AS patients. In contrast, STE-derived 2-D global longitudinal strain (GLS) is a validated and sensitive parameter to quantify LV longitudinal systolic function $[8,9]$. Several studies have demonstrated a reduced magnitude of GLS in AS patients compared to controls despite a preserved LV ejection fraction [16-18, 31-33]. In asymptomatic AS, GLS at rest has been shown to be independently associated with development of symptoms, an abnormal exercise tolerance, a need for AVR, and mortality [34-37]. Furthermore, a magnitude of the longitudinal strain of LV basal segments below $-13 \%$ has been found to be associated with a higher rate of cardiac events at follow-up [32]. It has also been shown that a GLS below $-18 \%$ predicts an abnormal exercise response with a sensitivity of $68 \%$ and a specificity of $77 \%$ [38]. In another study, the assessment of GLS during exercise had a higher accuracy than the LV ejection fraction to detect latent LV systolic dysfunction [39]. Finally, even the decrease in circumferential strain may be a marker of advanced disease with unfavorable course, particularly when it is associated with a low-flow state in AS patients [40]. These findings suggest that both regional and GLS have a greater and earlier diagnostic power than the LV ejection fraction in this clinical setting [41]. The advantages and limitations of the STE-derived GLS assessment are summarized in Table 1. 
Table 2. Studies showing relationships between myocardial fibrosis and LV systolic function assessed by different methods

\begin{tabular}{|c|c|c|c|c|}
\hline Study & $\begin{array}{l}\text { Patients, } \\
n\end{array}$ & $\begin{array}{l}\text { MF } \\
\text { type }\end{array}$ & Methods & Study results \\
\hline Weidemann et al. [14] & 85 & FMF & $\begin{array}{l}\text { LGE CMR, histology, } \\
\text { GLS }\end{array}$ & $\begin{array}{l}\text { The extent of histologically determined that cardiac fibrosis } \\
\text { at baseline correlated closely with markers of LS function } \\
\text { (all } p<0.001 \text { ) but not global LVEF }\end{array}$ \\
\hline Milano et al. [3] & 99 & FMF & $\begin{array}{l}\text { Histology, } \\
\text { LVEF }\end{array}$ & $\begin{array}{l}\text { MF was inversely related to LV fractional shortening } \\
(r=-0.64, p<0.001), \mathrm{LVEF}(r=-0.53, p<0.001) \text {, and } \\
\text { LV relative wall thickness }(r=-0.70, p<0.001)\end{array}$ \\
\hline Treibel et al. [15] & 133 & $\begin{array}{l}\text { FMF, } \\
\text { DMF }\end{array}$ & $\begin{array}{l}\text { LGE CMR, ECV, } \\
\text { histology }\end{array}$ & $\begin{array}{l}\text { High ECV was associated with worse LV remodeling, LVEF, } \\
\text { and functional capacity }\end{array}$ \\
\hline Dweck et al. [18] & 143 & MF & $\begin{array}{l}\text { LGE CMR, } \\
\text { LVEF }\end{array}$ & $\begin{array}{l}\text { Midwall fibrosis has an incremental prognostic value to } \\
\text { LVEF and may provide a useful method of risk stratification }\end{array}$ \\
\hline Chin et al. [19] & 166 & $\begin{array}{l}\text { FMF, } \\
\text { DMF }\end{array}$ & $\begin{array}{l}\text { LGE CMR, ECV, } \\
\text { histology }\end{array}$ & $\begin{array}{l}\text { Index ECV demonstrated a good correlation with DMF on } \\
\text { myocardial biopsies; there was evidence of increasing } \\
\text { hypertrophy, myocardial injury, diastolic dysfunction, and } \\
\text { LS dysfunction consistent with progressive LV } \\
\text { decompensation (all } p<0.05 \text { ) }\end{array}$ \\
\hline Kockova et al. [24] & 40 & $\mathrm{DMF}$ & $\begin{array}{l}\text { CMR T1, ECV, } \\
\text { histology, }\end{array}$ & $\begin{array}{l}\text { Both native T1 relaxation time with a cutoff value } \geq 1,010 \mathrm{~ms} \\
\text { and ECV with a cutoff value } \geq 0.32 \text { showed a high accuracy in } \\
\text { identifying severe }(>30 \%) \text { DMF } \\
\text { Native T1 relaxation time showed a significant correlation } \\
\text { with LV mass }(p<0.01)\end{array}$ \\
\hline Fabiani et al. [29] & 36 & MF & $\begin{array}{l}\text { Histology, } \\
\text { GLS }\end{array}$ & $\begin{array}{l}\text { MF is associated with alterations of regional and GLS } \\
\text { Plasmatic miRNA- } 21 \text { is directly related to MF and associated } \\
\text { with LV structural and functional impairment }\end{array}$ \\
\hline Hoffmann et al. [44] & 30 & FMF & LGE CMR, GLS & $\begin{array}{l}\text { There was a negative correlation between the amount of } \\
\text { MF determined by LGE CMR and peak systolic longitudinal } \\
\text { strain for the total LV }(r=-0.538, p=0.007)\end{array}$ \\
\hline Lee et al. [45] & 80 & $\mathrm{DMF}$ & CMR T1, GLS & $\begin{array}{l}\text { Native T1 correlated significantly with GLS measured with } \\
2 \text {-D STE }(r=0.598, p<0.001)\end{array}$ \\
\hline Bull et al. [46] & 109 & $\mathrm{DMF}$ & $\begin{array}{l}\text { CMR T1, } \\
\text { histology }\end{array}$ & $\begin{array}{l}\text { T1 values increased with greater LV mass indices and } \\
\text { correlated with the degree of biopsy-quantified fibrosis } \\
(r=0.36, p=0.008)\end{array}$ \\
\hline
\end{tabular}

LVEF, left ventricle ejection fraction; STE, speckle tracking echocardiography; GLS, global longitudinal strain; LS, longitudinal systolic; CMR, cardiac magnetic resonance; MF, nonspecific myocardial fibrosis; DMF, diffuse myocardial fibrosis; FMF, focal myocardial fibrosis; LGE, late gadolinium enhancement; ECV, extracellular volume.

\section{Relationship between Myocardial Fibrosis and LV Systolic Function}

Different kinds of observations have shown that GLS is a functional marker of myocardial fibrosis. First of all, GLS was found to be related to biomarkers of myocardial fibrosis such as those expressing calcification, collagen formation, or breakdown and inflammation [42, 43]. Several studies have also reported significant associations between LV systolic function and both FMF and DMF at CMR or myocardial histology [3, 14, 15, 18, 19, 24, 29, 44-46] (Table 2). Former studies have investigated the relationship between FMF and LV contractile function [14, 44, 45]. It has been shown that both the presence and the extent of FMF are inversely related to echocardiographic parameters such as relative wall thickness, LV fractional shortening, and ejection fraction and to STE-derived indices of LV myocardial function $[18,28,44]$. A GLS $\leq-11.6 \%$ showed a sensitivity of $65 \%$ and a specificity of $75 \%$ to predict significant FMF (LGE >10\%) [43]. The majority of studies 

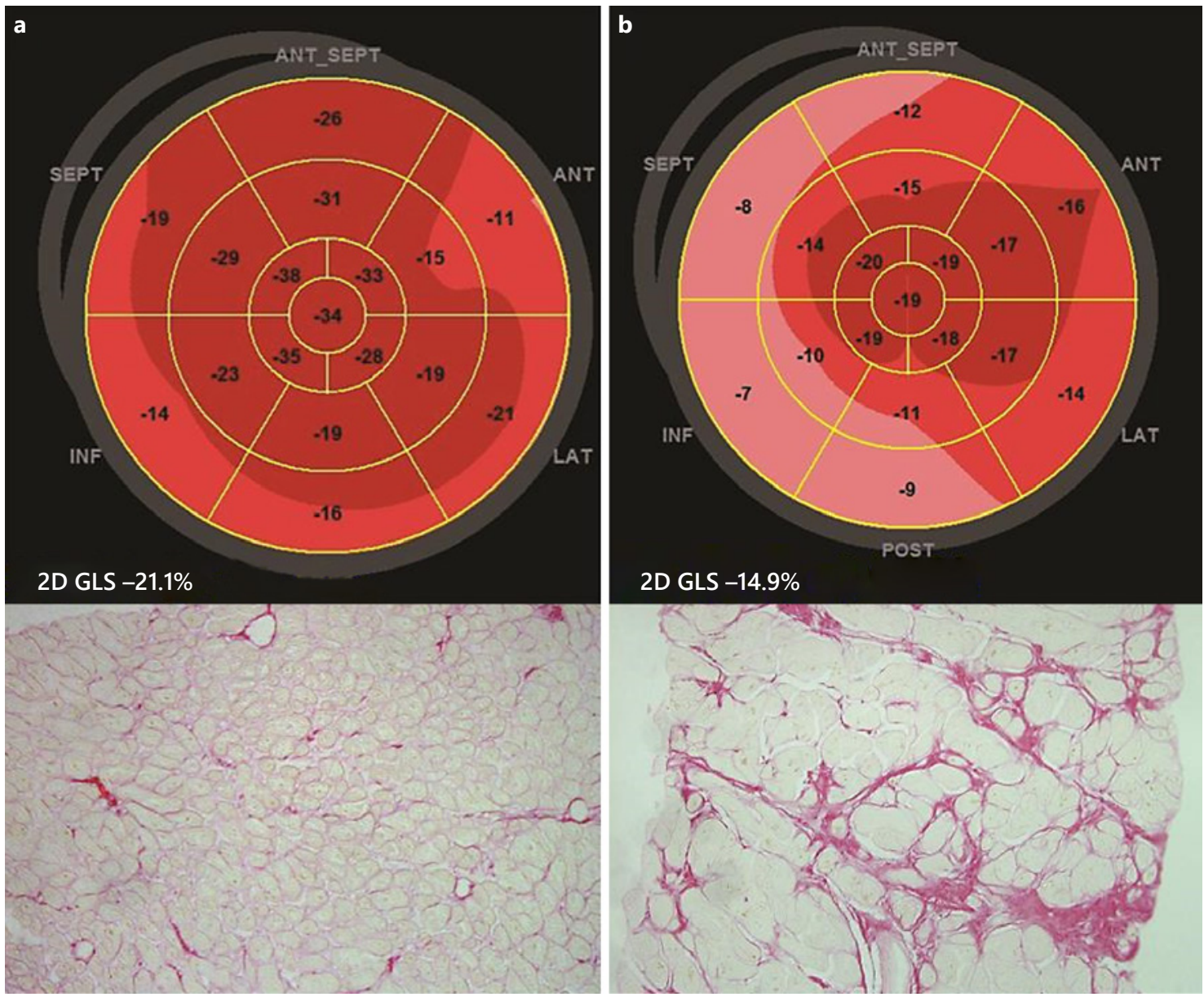

Fig. 1. Examples of resting 2-D GLS compared with the extent of DMF on myocardial histology. a Patient with a preserved magnitude of 2-D GLS (-21.1\%) and a negligible extent of DMF (7.4\%). b Patient with a reduced magnitude of 2-D GLS (-14.9\%) and extensive DMF (31.2\%). DMF, diffuse myocardial fibrosis; GLS, global longitudinal strain. The images are shown with permission from the research work group of the Cardiovascular Center Aalst (Belgium) [23, 24].

dealing with this issue have focused on DMF $[15,19,24$, $46,47]$. Of the conventional echocardiography-derived parameters, DMF seems to show a significant, though weak, correlation only with LV mass and the LV mass index $[23,24]$. In contrast to FMF, none of the other conventional parameters including LV ejection fraction or aortic valve area had a significant association with the degree of DMF [39]. This emphasizes the need to use a highly sensitive technique to assess DMF. Recent investigations have reported a significant relationship among DMF at histology, the CMR-T1-derived native $\mathrm{T} 1$ relaxation time or ECV, and STE-derived deformation indices [15, 18, 45]. In our study, a GLS $<-15 \%$ showed excellent accuracy to predict extensive (>30\%) DMF (Fig. 1, 2) [23, 24]. Moreover, we observed a significant correlation between GLS during exercise and native T1 relaxation time (Fig. 3) [23, 24]. Finally, the native $\mathrm{T} 1$ relaxation time showed a high accuracy in predicting the limited LV contractile reserve [23, 24]. All together these results strongly support the concept that GLS could be considered as an accurate functional marker of DMF in AS.

\section{Limitations}

Although both CMR-T1 and STE seem to have great clinical potential in various cardiovascular diseases, these techniques also have several limitations (Table 1). One of the major shortcomings of both methods is the great interscanner or intervendor variability of normal values. This 


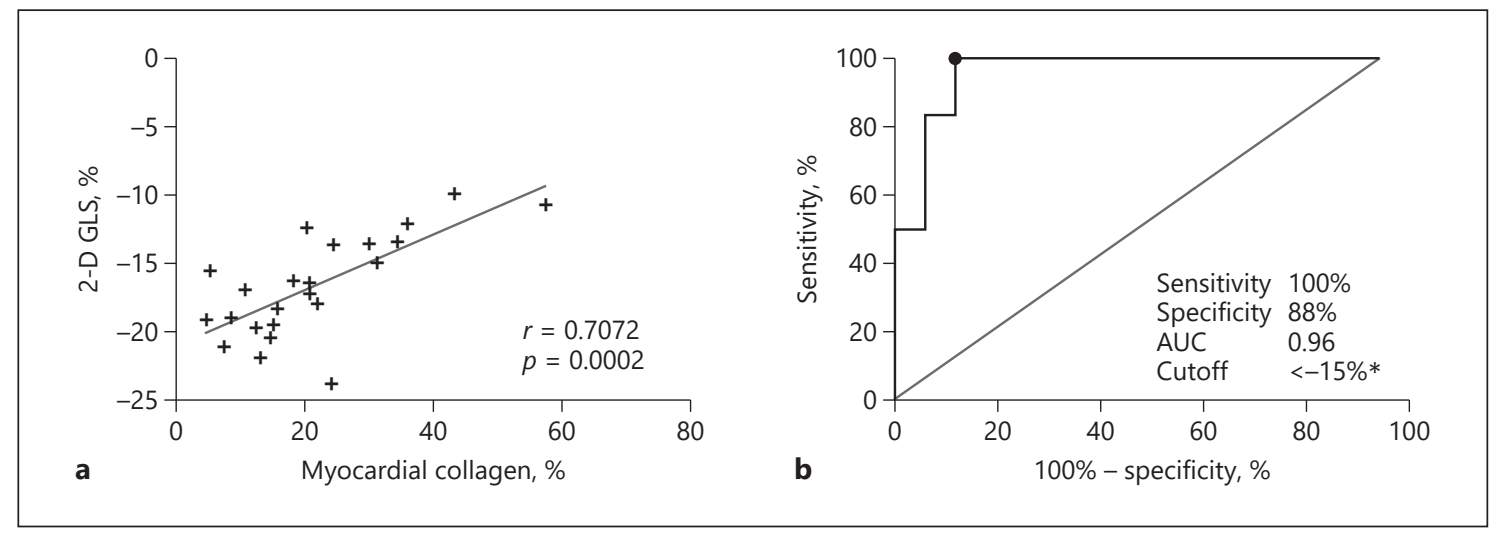

Fig. 2. a Correlation between 2-D GLS and the percentage of myocardial collagen on myocardial histology. b Accuracy of resting 2-D GLS to identify extensive (>30\%) DMF on myocardial histology. DMF, diffuse myocardial fibrosis; GLS, global longitudinal strain. The images are shown w permission from the research work group of the Cardiovascular Center Aalst [23, 24].

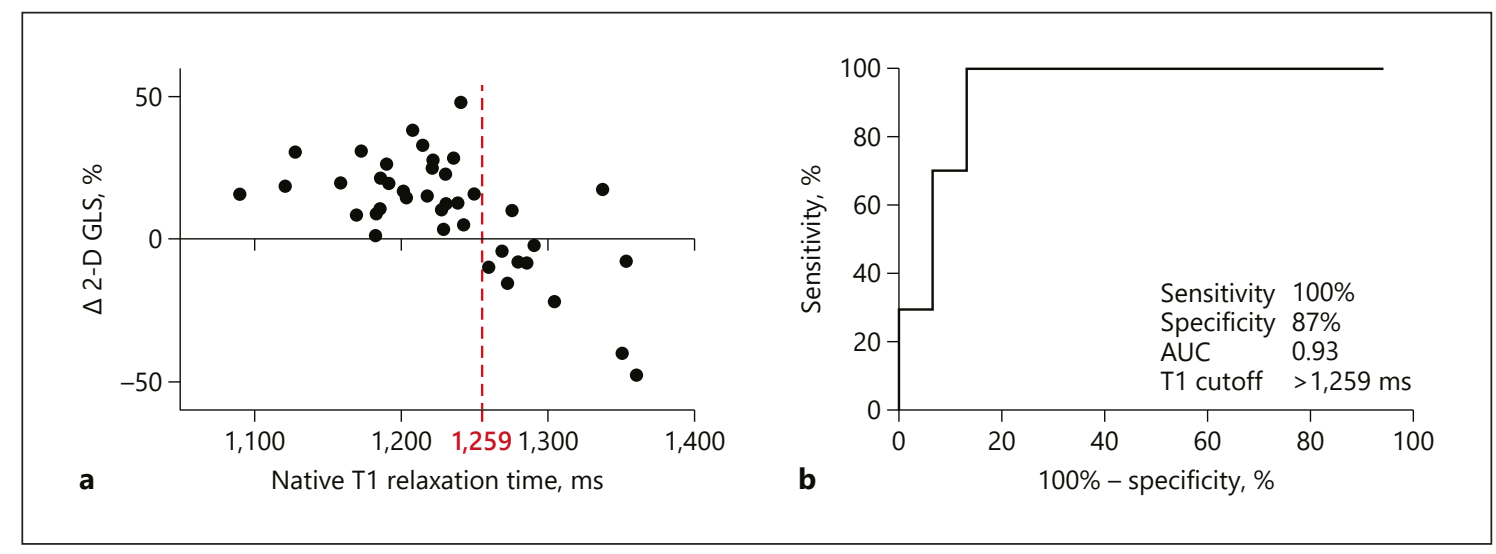

Fig. 3. a Correlation between exercise-induced $\Delta 2-\mathrm{D}$ GLS and native T1 relaxation time on a 3-T scan. b Accuracy of native T1 relaxation time on a 3-T scan to predict a reduced LV contractile reserve. DMF, diffuse myocardial fibrosis; GLS, global longitudinal strain. The images are shown with permission from research work group of the Cardiovascular Center Aalst [23, 24].

disadvantage requires definition of normal values for each individual scanner or echo device when assessing healthy subjects. This procedure should be repeated after each major update of equipment or hardware. Other limitations need also mentioned. First of all, CMR-derived assessment of FMF using LGE has a wide interobserver variability, depends on the technical setting of the scanner, and does not allow detection of DMF [47]. The CMR-T1-derived T1 relaxation time and ECV are dependent on a specific CMRT1 sequence, magnetic field strength, and homogeneity. In addition, there is a significant overlap between T1 mapping values in healthy and diseased myocardia, making the interpretation challenging $[15,30,39,40]$. Other limitations of CMR include the limited availability of equipment and expertise, the associated high costs, and the need to administer a contrast agent. In contrast, echocardiography is more widely available, faster, and cheaper than CMR. GLS, a relatively operator-independent parameter, has a higher reproducibility compared to LV ejection fraction and other echocardiographic parameters of LV systolic function [6]. However, due to the difference among different vendors, the same software should be used in individual patients over time [48-50]. The load dependency of the STE-derived indices may represent another challenge for routine clinical use in AS, as they are largely influenced by both preload and afterload changes [27, 38, 39, 51]. According to recent published studies in animal models, STEderived indices correlate strongly with pressure-volume 
loop-derived contractility indices and the STE-derived strain cannot predict load-independent contractility [51, 52]. Accordingly, to bypass this limitation in the chronic overloaded LV, the pressure-strain loop-based method is a promising tool for assessment and monitoring of myocardial function in patients with AS, but this method is still under investigation. Recently, novel techniques of derived tissue tracking by CMR cine acquisitions, such as CMR tagging and feature tracking, have provided a detailed characterization of LV global and regional contractility and reasonable agreement in the assessment of myocardial deformation in patients with AS [53-55]. However, several technical limitations may affect quantitative results and lead to variability among different readers [56-58]. Finally, the role of tissue tracking by CMR in detection of the extent and types of myocardial fibrosis could be compromised by the coexistence of other comorbidities, such as hypertension, amyloidosis, or ischemic heart disease, which may play a role in disease phenotyping $[59,60]$. Thus, the accuracy of these emerging methods for characterization of LV performance and quantification of myocardial fibrosis in patients with isolated AS or a concomitant comorbidity is still not adequately identified [61-64].

\section{Conclusions}

There is growing evidence that myocardial fibrosis plays an important role in the pathophysiology of AS and its complications. Recent advances in cardiac imaging technology allow noninvasive detection of myocardial fi- brosis and the associated impairment of LV systolic function. It has been demonstrated that evaluation of myocardial fibrosis by CMR and of its functional consequences highlighted by GLS provides a more accurate assessment of early myocardial damage than LV ejection fraction. Despite its great diagnostic potential, further improvement of the current technology is needed to homogenize CMR-T1- and STE-derived indices across different vendors and scanners. Future advances in noninvasive cardiac imaging might improve our understating of the interplay between myocardial fibrosis and LV function. The real clinical value of these parameters reflecting early myocardial injury needs to be validated in multicenter prospective studies.

However, the encouraging results derived from different studies provide clinical perspectives on the use of these techniques for guidance in clinical decision making and improvement of the management of patients with AS.

\section{Acknowledgement}

Dr. Katbeh was supported by a research grant from the International PhD programme in Cardiovascular Pathophysiology and Therapeutics (CardioPaTh).

\section{Disclosure Statement}

The authors have no conflicts of interest to declare.

\section{References}

1 Baumgartner H, Falk V, Bax JJ, De Bonis M, Hamm C, Holm PJ, et al.; ESC Scientific Document Group. 2017 ESC/EACTS Guidelines for the management of valvular heart disease. Eur Heart J. 2017 Sep;38(36):2739-91.

2 Nishimura RA, Otto CM, Bonow RO, Carabello BA, Erwin JP 3rd, Fleisher LA, et al. 2017 AHA/ACC Focused Update of the 2014 AHA/ACC Guideline for the Management of Patients With Valvular Heart Disease: A Report of the American College of Cardiology/ American Heart Association Task Force on Clinical Practice Guidelines. J Am Coll Cardiol. 2017 Jul;70(2):252-89.

3 Milano AD, Faggian G, Dodonov M, Golia G, Tomezzoli A, Bortolotti U, et al. Prognostic value of myocardial fibrosis in patients with severe aortic valve stenosis. J Thorac Cardiovasc Surg. 2012 Oct;144(4):830-7.
4 Treibel TA, Kozor R, Schofield R, Benedetti G, Fontana M, Bhuva AN, et al. Reverse Myocardial Remodeling Following Valve Replacement in Patients With Aortic Stenosis. J Am Coll Cardiol. 2018 Feb;71(8):860-71.

5 Kwiecinski J, Chin CW, Everett RJ, White AC, Semple S, Yeung E, et al. Adverse prognosis associated with asymmetric myocardial thickening in aortic stenosis. Eur Heart J Cardiovasc Imaging. 2018 Mar; 19(3):347-56.

6 Kvernby S, Rönnerfalk M, Warntjes M, Carlhäll CJ, Nylander E, Engvall J, et al. Longitudinal changes in myocardial $\mathrm{T} 1$ and $\mathrm{T} 2$ relaxation times related to diffuse myocardial fibrosis in aortic stenosis; before and after aortic valve replacement. J Magn Reson Imaging. 2018 Feb;48(3):799-807.
7 Podlesnikar T, Delgado V, Bax JJ. Cardiovascular magnetic resonance imaging to assess myocardial fibrosis in valvular heart disease. Int J Cardiovasc Imaging. 2018 Jan;34(1):97112 .

8 Kempny A, Diller GP, Kaleschke G, Orwat S, Funke A, Radke R, et al. Longitudinal left ventricular 2D strain is superior to ejection fraction in predicting myocardial recovery and symptomatic improvement after aortic valve implantation. Int J Cardiol. 2013 Sep;167(5): 2239-43.

9 Cengiz B, Şahin ŞT, Yurdakul S, Kahraman S, Bozkurt A, Aytekin S. Subclinical left ventricular systolic dysfunction in patients with severe aortic stenosis: A speckle-tracking echocardiography study. Turk Kardiyol Dern Ars. 2018 Jan;46(1):18-24. 
10 Rader F, Sachdev E, Arsanjani R, Siegel RJ. Left ventricular hypertrophy in valvular aortic stenosis: mechanisms and clinical implications. Am J Med. 2015 Apr;128(4):344-52.

11 Dweck MR, Joshi S, Murigu T, Gulati A, Alpendurada F, Jabbour A, et al. Left ventricular remodeling and hypertrophy in patients with aortic stenosis: insights from cardiovascular magnetic resonance. J Cardiovasc Magn Reson. 2012 Jul;14(1):50.

12 Dahl JS, Christensen NL, Videbæk L, Poulsen MK, Carter-Storch R, Hey TM, et al. Left ventricular diastolic function is associated with symptom status in severe aortic valve stenosis. Circ Cardiovasc Imaging. 2014 Jan;7(1):1428.

13 Golia G, Milano AD, Dodonov M, Bergamini C, Faggian G, Tomezzoli A, et al. Influence of myocardial fibrosis on left ventricular hypertrophy in patients with symptomatic severe aortic stenosis. Cardiology. 2011;120(3):13945.

14 Weidemann F, Herrmann S, Störk S, Niemann M, Frantz S, Lange V, et al. Impact of myocardial fibrosis in patients with symptomatic severe aortic stenosis. Circulation. 2009 Aug;120(7):577-84.

15 Treibel TA, López B, González A, Menacho K, Schofield RS, Ravassa S, et al. Reappraising myocardial fibrosis in severe aortic stenosis: an invasive and non-invasive study in $133 \mathrm{pa}$ tients. Eur Heart J. 2018 Feb;39(8):699-709.

16 Azevedo CF, Nigri M, Higuchi ML, Pomerantzeff PM, Spina GS, Sampaio RO, et al. Prognostic significance of myocardial fibrosis quantification by histopathology and magnetic resonance imaging in patients with severe aortic valve disease. J Am Coll Cardiol. 2010 Jul;56(4):278-87.

17 Jellis C, Martin J, Narula J, Marwick TH. Assessment of nonischemic myocardial fibrosis. J Am Coll Cardiol. 2010 Jul;56(2):89-97.

18 Dweck MR, Joshi S, Murigu T, Alpendurada F, Jabbour A, Melina G, et al. Midwall fibrosis is an independent predictor of mortality in patients with aortic stenosis. J Am Coll Cardiol. 2011 Sep;58(12):1271-9.

19 Chin CW, Everett RJ, Kwiecinski J, Vesey AT, Yeung E, Esson G, et al. Myocardial fibrosis and cardiac decompensation in aortic stenosis. JACC Cardiovasc Imaging. 2017 Nov; 10(11):1320-33.

20 Adda J, Mielot C, Giorgi R, Cransac F, Zirphile X, Donal E, et al. Low-flow, low-gradient severe aortic stenosis despite normal ejection fraction is associated with severe left ventricular dysfunction as assessed by speckle-tracking echocardiography: a multicenter study. Circ Cardiovasc Imaging. 2012 Jan;5(1):27-35.

21 Hachicha Z, Dumesnil JG, Bogaty P, Pibarot P. Paradoxical low-flow, low-gradient severe aortic stenosis despite preserved ejection fraction is associated with higher afterload and reduced survival. Circulation. 2007 Jun; 115(22):2856-64.
22 Fontana M, White SK, Banypersad SM, Sado DM, Maestrini V, Flett AS, et al. Comparison of T1 mapping techniques for ECV quantification. Histological validation and reproducibility of ShMOLLI versus multibreath-hold T1 quantification equilibrium contrast CMR. J Cardiovasc Magn Reson. 2012 Dec;14(1):88.

23 Kockova R, Kacer P, Pirk J, Maly J, Vsianska $\mathrm{M}$, Sukupova L, et al. Magnetic resonance-derived pre-contrast $\mathrm{T} 1$ relaxation time is the accurate marker of diffuse myocardial fibrosis in severe aortic valve disease: a comparison with left ventricular myocardial biopsy. Circulation. 2015;132:A13596.

24 Kockova R, Kacer P, Pirk J, Maly J, Sukupova L, Sikula V, et al. Native T1 Relaxation Time and Extracellular Volume Fraction as Accurate Markers of Diffuse Myocardial Fibrosis in Heart Valve Disease - Comparison With Targeted Left Ventricular Myocardial Biopsy. Circ J. 2016 Apr;80(5):1202-9.

25 Sibley CT, Noureldin RA, Gai N, Nacif MS, Liu S, Turkbey EB, et al. T1 Mapping in cardiomyopathy at cardiac MR: comparison with endomyocardial biopsy. Radiology. 2012 Dec; 265(3):724-32.

26 Puntmann VO, Voigt T, Chen Z, Mayr M, Karim R, Rhode K, et al. Native T1 mapping in differentiation of normal myocardium from diffuse disease in hypertrophic and dilated cardiomyopathy. JACC Cardiovasc Imaging. 2013 Apr;6(4):475-84.

27 Ugander M, Oki AJ, Hsu LY, Kellman P, Greiser A, Aletras AH, et al. Extracellular volume imaging by magnetic resonance imaging provides insights into overt and sub-clinical myocardial pathology. Eur Heart J. 2012 May; 33(10):1268-78.

28 Treibel TA, Fontana M, Reant P, Espinosa MA, Castelletti S, Herrey AS, et al. T1 mapping in severe aortic stenosis: insights into LV remodeling. J Cardiovasc Magn Reson. 2015; 17 Suppl 1:17.

29 Fabiani I, Scatena C, Mazzanti CM, Conte L, Pugliese NR, Franceschi S, et al. MicroRNA-21 (biomarker) and global longitudinal strain (functional marker) in detection of myocardial fibrotic burden in severe aortic valve stenosis: a pilot study. J Transl Med. 2016 Aug; 14(1):248.

30 Chin CW, Semple S, Malley T, White AC, Mirsadraee S, Weale PJ, et al. Optimization and comparison of myocardial $\mathrm{T} 1$ techniques at $3 \mathrm{~T}$ in patients with aortic stenosis. Eur Heart J Cardiovasc Imaging. 2014 May;15(5):556-65.

31 Delgado V, Tops LF, van Bommel RJ, van der Kley F, Marsan NA, Klautz RJ, et al. Strain analysis in patients with severe aortic stenosis and preserved left ventricular ejection fraction undergoing surgical valve replacement. Eur Heart J. 2009 Dec;30(24):3037-47.

32 Kearney LG, Lu K, Ord M, Patel SK, Profitis $\mathrm{K}$, Matalanis G, et al. Global longitudinal strain is a strong independent predictor of allcause mortality in patients with aortic stenosis. Eur Heart J Cardiovasc Imaging. 2012 Oct;13(10):827-33.
33 Kusunose K, Goodman A, Parikh R, Barr T, Agarwal S, Popovic ZB, et al. Incremental prognostic value of left ventricular global longitudinal strain in patients with aortic stenosis and preserved ejection fraction. Circ Cardiovasc Imaging. 2014 Nov;7(6):938-45.

34 Carstensen HG, Larsen LH, Hassager C, Kofoed KF, Jensen JS, Mogelvang R. Basal longitudinal strain predicts future aortic valve replacement in asymptomatic patients with aortic stenosis. Eur Heart J Cardiovasc Imaging. 2016 Mar;17(3):283-92.

35 Dulgheru R, Magne J, Davin L, Nchimi A, Oury C, Pierard LA, et al. Left ventricular regional function and maximal exercise capacity in aortic stenosis. Eur Heart J Cardiovasc Imaging. $2016 \mathrm{Feb} ; 17(2): 217-24$.

36 Lafitte S, Perlant M, Reant P, Serri K, Douard $\mathrm{H}$, DeMaria A, et al. Impact of impaired myocardial deformations on exercise tolerance and prognosis in patients with asymptomatic aortic stenosis. Eur J Echocardiogr. 2009 May; 10(3):414-9.

37 Yingchoncharoen T, Gibby C, Rodriguez LL, Grimm RA, Marwick TH. Association of myocardial deformation with outcome in asymptomatic aortic stenosis with normal ejection fraction. Circ Cardiovasc Imaging. 2012 Nov;5(6):719-25.

38 Călin A, Roşca M, Beladan CC, Enache R, Mateescu $\mathrm{AD}$, Ginghină $\mathrm{C}$, et al. The left ventricle in aortic stenosis-imaging assessment and clinical implications. Cardiovasc Ultrasound. 2015 Apr;13(1):22.

39 Donal E, Thebault C, O'Connor K, Veillard D, Rosca M, Pierard L, et al. Impact of aortic stenosis on longitudinal myocardial deformation during exercise. Eur J Echocardiogr. 2011 Mar;12(3):235-41.

$40 \mathrm{Ng} \mathrm{AC}$, Delgado V, Bertini M, Antoni ML, van Bommel RJ, van Rijnsoever EP, et al. Alterations in multidirectional myocardial functions in patients with aortic stenosis and preserved ejection fraction: a two-dimensional speckle tracking analysis. Eur Heart J. 2011 Jun;32(12):1542-50.

41 Bruch C, Stypmann J, Grude M, Gradaus R, Breithardt G, Wichter T. Tissue Doppler imaging in patients with moderate to severe aortic valve stenosis: clinical usefulness and diagnostic accuracy. Am Heart J. 2004 Oct;148(4): 696-702.

42 Kang SJ, Lim HS, Choi BJ, Choi SY, Hwang GS, Yoon MH, et al. Longitudinal strain and torsion assessed by two-dimensional speckle tracking correlate with the serum level of tissue inhibitor of matrix metalloproteinase-1, a marker of myocardial fibrosis, in patients with hypertension. J Am Soc Echocardiogr. 2008 Aug;21(8):907-11.

43 Kapelouzou A, Tsourelis L, Kaklamanis L, Degiannis D, Kogerakis N, Cokkinos DV. Serum and tissue biomarkers in aortic stenosis. Glob Cardiol Sci Pract. 2015 Nov;2015(4):49. 
44 Hoffmann R, Altiok E, Friedman Z, Becker M, Frick M. Myocardial deformation imaging by two-dimensional speckle-tracking echocardiography in comparison to late gadolinium enhancement cardiac magnetic resonance for analysis of myocardial fibrosis in severe aortic stenosis. Am J Cardiol. 2014 Oct;114(7): 1083-8.

45 Lee SP, Lee W, Lee JM, Park EA, Kim HK, Kim YJ, et al. Assessment of diffuse myocardial fibrosis by using MR imaging in asymptomatic patients with aortic stenosis. Radiology. 2015 Feb;274(2):359-69.

46 Bull S, White SK, Piechnik SK, Flett AS, Ferreira VM, Loudon M, et al. Human non-contrast $\mathrm{T} 1$ values and correlation with histology in diffuse fibrosis. Heart. 2013 Jul;99(13): 932-7.

47 Bluemke DA, Pattanayak P. Tissue characterization of the myocardium by MR and CT imaging. Radiol Clin North Am. 2015 Mar; 53(2):413-23.

48 Mądry W, Karolczak MA. Physiological basis in the assessment of myocardial mechanics using speckle-tracking echocardiography $2 \mathrm{D}$. Part I. J Ultrason. 2016 Jun;16(65):135-44.

49 Farsalinos KE, Daraban AM, Unnlü S, Thomas JD, Badano LP, Voigt JU. Head-to-Head Comparison of Global Longitudinal Strain Measurements among Nine Different Vendors: The EACVI/ASE Inter-Vendor Comparison Study. J Am Soc Echocardiogr. 2015 Oct;28(10):1171-1181, e2.

50 Ünlü S, Mirea O, Duchenne J, Pagourelias ED, Bézy S, Thomas JD, et al. Comparison of Feasibility, Accuracy, and Reproducibility of Layer-Specific Global Longitudinal Strain Measurements Among Five Different Vendors: A Report from the EACVI-ASE Strain Standardization Task Force. J Am Soc Echocardiogr. 2018 Mar;31(3):374-380.e1.
51 Bauer F, Bénigno S, Lemercier M, Tapiéro S, Eltchaninoff $\mathrm{H}$, Tron C, et al. Early improvement of left ventricular function after implantation of a transcutaneous aortic valve: a tissue Doppler ultrasound study. Arch Cardiovasc Dis. 2009 Apr;102(4):311-8.

52 Kovács A, Oláh A, Lux Á, Mátyás C, Németh BT, Kellermayer D, et al. Strain and strain rate by speckle-tracking echocardiography correlate with pressure-volume loop-derived contractility indices in a rat model of athlete's heart. Am J Physiol Heart Circ Physiol. 2015 Apr;308(7):H743-8.

53 Dahle GO, Stangeland L, Moen CA, Salminen PR, Haaverstad R, Matre K, et al. The influence of acute unloading on left ventricular strain and strain rate by speckle tracking echocardiography in a porcine model. Am J Physiol Heart Circ Physiol. 2016 May;310(10): H1330-9.

54 Nagel E, Stuber M, Burkhard B, Fischer SE, Scheidegger MB, Boesiger $\mathrm{P}$, et al. Cardiac rotation and relaxation in patients with aortic valve stenosis. Eur Heart J. 2000 Apr;21(7): 582-9.

55 Sandstede JJ, Johnson T, Harre K, Beer M, Hofmann S, Pabst T, et al. Cardiac systolic rotation and contraction before and after valve replacement for aortic stenosis: a myocardial tagging study using MR imaging. AJR Am J Roentgenol. 2002 Apr;178(4):953-8.

56 Al Musa T, Uddin A, Swoboda PP, Garg P, Fairbairn TA, Dobson LE, et al. Myocardial strain and symptom severity in severe aortic stenosis: insights from cardiovascular magnetic resonance. Quant Imaging Med Surg. 2017 Feb;7(1):38-47.

57 Schneeweis C, Lapinskas T, Schnackenburg B, Berger A, Hucko T, Kelle S, et al. Comparison of myocardial tagging and feature tracking in patients with severe aortic stenosis. J Heart Valve Dis. 2014 Jul;23(4):432-40.
58 Singh A, Steadman CD, Khan JN, Horsfield MA, Bekele S, Nazir SA, et al. Intertechnique agreement and interstudy reproducibility of strain and diastolic strain rate at 1.5 and 3 Tesla: a comparison of feature-tracking and tagging in patients with aortic stenosis. J Magn Reson Imaging. 2015 Apr;41(4):1129-37.

59 Chin CW, Messika-Zeitoun D, Shah AS, Lefevre G, Bailleul S, Yeung EN, et al. A clinical risk score of myocardial fibrosis predicts adverse outcomes in aortic stenosis. Eur Heart J. 2016 Feb;37(8):713-23.

60 Treibel TA, Kozor R, Fontana M, Torlasco C, Reant P, Badiani S, et al. Sex Dimorphism in the Myocardial Response to Aortic Stenosis. JACC Cardiovasc Imaging. 2017 Nov.

61 Bax JJ, Delgado V. Advanced imaging in valvular heart disease. Nat Rev Cardiol. 2017 Apr;14(4):209-23.

62 Muraru D, Niero A, Rodriguez-Zanella H, Cherata D, Badano L. Three-dimensional speckle-tracking echocardiography: benefits and limitations of integrating myocardial mechanics with three-dimensional imaging. Cardiovasc Diagn Ther. 2018 Feb;8(1):10117.

63 Dulgheru R, Pibarot P, Sengupta PP, Piérard LA, Rosenhek R, Magne J, et al.; Viewpoint of the Heart Valve Clinic International Database (HAVEC) Group. Multimodality Imaging Strategies for the Assessment of Aortic Stenosis: Viewpoint of the Heart Valve Clinic International Database (HAVEC) Group. Circ Cardiovasc Imaging. 2016 Feb;9(2):e004352.

64 Scully PR, Bastarrika G, Moon JC, Treibel TA. Myocardial Extracellular Volume Quantification by Cardiovascular Magnetic Resonance and Computed Tomography. Curr Cardiol Rep. 2018 Mar;20(3):15. 